\title{
On the hydration of ions
}

\author{
K.Heinzinger, H. Schäfer \\ Max-Planck-Institut für Chemie (Otto-Hahn-Institut) \\ D-55020 Mainz, Germany
}

Received November 5, 1998

\begin{abstract}
This report will concentrate on ions which are produced in nuclear power reactors and/or which are of special interest because of their small radius and/or their high charges, leading to hydrolysis. Mainly the results of Molecular Dynamics simulations will be discussed as they are able to provide a comprehensive and consistent description of the structural and dynamical properties of the water molecules in the hydration shells of the ions. Whenever reactions between the ions and the water molecules can occur, it will be necessary to employ ab initio simulations such as the Car-Parinello method. The difficulties connected with the investigation of uranium and plutonium ions with this method are discussed.
\end{abstract}

Key words: hydrolysis, molecular dynamics, Car-Parinello method, actinides

PACS: $61.20 . Q, 61.20 . J, 71.15 . P d$

\section{Introduction}

In this report the structural and dynamical properties of electrolyte solutions will be discussed as far as they can be deduced from computer simulations. The data presented will concentrate on ions which can be found in nuclear power reactors like the one in Chernobyl. It is aimed at forming a basis for further discussions within the framework of the INTAS-project concerned with the "Investigation of Complex Formation and Ionic Transport Processes in Water, Aqueous Solutions and H-Bonded Systems for the Development of Environmental Protection Solutions Connected with Water Pollution".

The radioactive decay needs not to be considered in computer simulations since it happens so scarcely that the changes in the structural and dynamical properties of the solutions will not be statistically significant, considering the small number of particles involved (e.g. 10 ions and several hundred water molecules) and the limited length of the simulation time $\left(10^{-10} \mathrm{~s}\right)$. Thus, only the stable isotopes of the relevant ions will be considered here. Although this simplification follows from the simulation method, the question remains open whether the radioactive decay would at all influence the properties which are of interest here. 
Decisive for the reliability of the results derived from the simulations are the potentials employed. As there is no a priori way to determine the quality of the potentials - independent of the way they have been deduced - the only possibility to check their quality is the comparison of the simulation results with experimental ones derived unambiguously from measurements. Once this agreement has been demonstrated, the MD simulation leads to a comprehensive description of the solution investigated. The simulation can, thus, predict properties which are not, not yet or not directly accessible by experiment and can explain measured macroscopic properties on a molecular level.

There is no problem to find the potentials for the simply charged large ions like the $\mathrm{Cs}^{+}$or $\mathrm{I}^{-}$as has been demonstrated quite some time ago [1]. The same results have been found whether empirical potentials have been employed or those derived from ab initio calculations. Similar arguments hold for the large doubly charged alkaline earth ions like e.g. strontium. The description of the ion-water interactions by pair potentials seems to be all right at least as far as the comparison of the calculated properties with experimental ones-like ion-oxygen distances, hydration numbers etc. - is concerned at moderate concentrations and at ambient temperatures. The question remains open whether more complicated data like e.g. the height of the maxima in the radial distribution functions (RDF) can be described correctly in this simple way or whether e.g. polarisibilities or charge transfer have to be included.

The simple pair potential approach is definitely not sufficient to describe correctly the hydration of the doubly charged small beryllium ion. This has been demonstrated by three different simulations employing pair potentials [2], three-body interactions [3], and the Car-Parinello method [4]. But another aspect of beryllium salt solutions is the hydrolysis, which was not considered in this simulation. Even more important is the hydrolysis caused by the aluminum ion. Similar to the beryllium case and in spite of large efforts to describe the ion-water interaction correctly no hydrolysis effects are taken into account directly in the relevant simulations [5]. Quite recently a first principle simulation was employed for the first time to investigate the hydrolysis of methyl chloride [6].

The hydrolysis of the hydrated ions is a very important aspect in the context of these investigations and cannot be neglected since uranium and plutonium ions show hydrolysis to a significant extent. Unfortunately, for the time being these ions cannot be treated by first principle simulations because of the large number of electrons involved. But quite recently a paper has been published in which the pKa values for various hydrated metal ions are related to the binding energies of the hydrated complexes derived from density functional calculations [7]. Even this approach seems to be too difficult to employ for uranium and plutonium ions and their oxides. 


\section{Structural and dynamical properties of the hydrated iodide, cesium and strontium ions}

From the ions considered in this chapter $\mathrm{I}^{-}$has been investigated most extensively. It has been demonstrated that structural and dynamical properties can be derived consistently. In addition, the hydration of $\mathrm{I}^{-}$near Lennard-Jones (LJ) and metal surfaces has been reported. For $\mathrm{Cs}^{+}$only structural properties have been calculated so far. But, if necessary, the same information as presented for the $\mathrm{I}^{-}$can be derived easily from an extended simulation. Different from $\mathrm{I}^{-}$and $\mathrm{Cs}^{+}$in the case of $\mathrm{Sr}^{2+}$ the effect of the ion on the intramolecular properties of water, such as geometry and vibrational frequencies, was investigated as a flexible water model was employed in the simulation.

The ion-oxygen and ion-hydrogen radial distribution functions (RDFs) for all three ions are presented in figure 1, together with the running integration numbers, $n(r)$. The hydration numbers in this chapter are defined as $n(r)$ at the position of the first minimum of the ion-oxygen RDF.

\subsection{The iodide ion}

\subsubsection{Structure}

The computer simulations show in reasonable agreement with experimental results that the large iodide ion is only weakly hydrated. At moderate concentration the first maximum in the I-O RDF (figure 1) appears at $3.65 \AA$ with a hydration number of about nine [8]. Simulations have been performed with the rigid ST2 model for water where the ion is described by a Lennard-Jones (LJ) sphere with an elementary charge in the centre [9] and with the flexible BJH model where the ionwater interactions are derived from ab initio calculations [10]. The results of the two simulations differ only in the height of the first peak in the I-O RDF, significantly higher for the one with the BJH model. The accuracy of the X-ray data as far as this property is concerned does not allow for a decision between the two potentials.

The hydration shell water molecules form preferentially linear hydrogen bonds with the iodide ion having a broad distribution of the orientations about this preferential direction. There is no well defined structure of the hydration shell water molecules, they are uniformly distributed around the ion.

Contrary to e.g. $\mathrm{Li}^{+}$an increase in temperature does not significantly effect the iodide hydration [11] as far as it has been deduced from a simulation of an LiI solution where the density has been kept constant while the temperature has been increased from 300 to $500 \mathrm{~K}$ which leads to a pressure of about $3 \mathrm{kbar}$. The changes in position and height of the first maximum of the I-O RDF as well as the hydration number caused by the temperature increase are not outside the limits of statistical uncertainty.

The structure and the dynamics of the hydrated $\mathrm{I}^{-}$has been investigated by computer simulation when it is near LJ-walls [12], at a $\mathrm{Pt}(100)$ [10] and a liquid mercury [13] surface. 


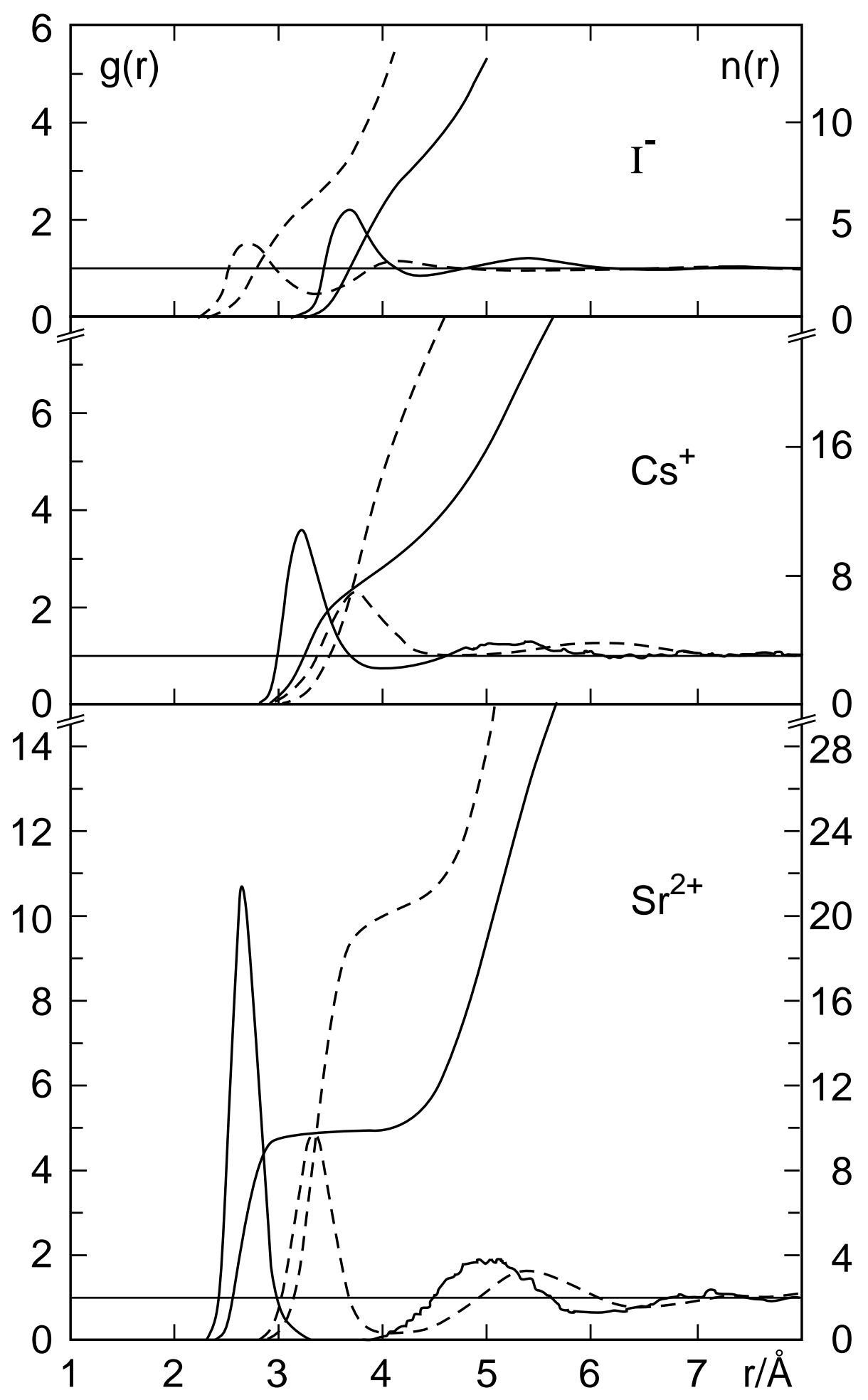

Figure 1. Ion-oxygen (full) and ion-hydrogen (dashed) radial distribution functions and running integration numbers from MD simulations of $2.2 \mathrm{~m}$ LiI, $2.2 \mathrm{~m}$ $\mathrm{CsF}$ and $1.1 \mathrm{~m} \mathrm{SrCl}_{2}$ solutions. 
Near the LJ-wall the heights of the first peaks in the I-O and I-H RDFs are slightly increased while the peak positions remain unchanged compared with the bulk solution. This means a small enhancement of the hydration shell structure as expected for hydrophobic interactions. Due to the steric effects, the hydration number is reduced from 8.7 in the bulk to 7.7 near the LJ-wall.

At both metal surfaces the iodide ion is contact adsorbed [14]. The excluded volume effect of the walls leads to a reduction of the hydration number to almost one half. The I-O and I-H RDFs at the liquid mercury surface are similar to those in the bulk solution because of the mobility of the first layer mercury atoms which permits a certain adjustment of the hydration shell structure of the ion to that in the bulk. They are different from those at the Pt(100) surface where a significant reduction of the heights of the first peaks can be found as a consequence of the formation of a rather rigid water overlayer.

\subsubsection{Dynamical properties}

The self-diffusion coefficients of $\mathrm{I}^{-}$can be calculated from the simulation by the Green-Kubo equation using the velocity autocorrelation function. Its Fourier transformation gives the spectral density of the hindered translational motion of $\mathrm{I}^{-}$. The self-diffusion coefficient of $\mathrm{I}^{-}$at ambient conditions can be calculated in this way to be $1.40 \pm 0.15 \cdot 10^{-5} \mathrm{~cm}^{2} / \mathrm{s}$ in good agreement with experimental data [15]. It is interesting to note that it is twice as large as that for the much smaller $\mathrm{Li}^{+}$. This difference can be explained by the much stronger interaction of $\mathrm{Li}^{+}$with its hydration shell water molecules as compared to the weakly hydrated $\mathrm{I}^{-}$. The $\mathrm{Li}^{+}$ can move only together with its six water molecules in the first hydration shell and, in addition, the simulation also shows that strong hydrogen bonds are formed between the first and the second shell which further reduces the self-diffusion of $\mathrm{Li}^{+}$. Therefore, the effective mass of $\mathrm{Li}^{+}$is significantly larger than that of $\mathrm{I}^{-}$.

This explanation is confirmed by the spectral densities of the hindered translations which show a strong peak at about 600 and $25 \mathrm{~cm}^{-1}$ for $\mathrm{Li}^{+}$and $\mathrm{I}^{-}$, respectively [16]. This shows that the $\mathrm{Li}^{+}$vibrates with a high frequency in the cage of its six octahedrally arranged first shell water molecules while the $\mathrm{I}^{-}$moves through the solution without hydration shell water molecules, colliding occasionally with a water molecule.

\subsection{The cesium ion}

The Cs-O and Cs-H RDFs together with the running integration numbers are shown in figure 1 for comparison with those of $\mathrm{I}^{-}$. They have been derived from an MD simulation of a $2.2 \mathrm{~m}$ CsF solution [17], the same concentration as used for the bulk LiI solution. The results for $\mathrm{Cs}^{+}$presented in figure 1 are slightly different from simulations of CsI solutions at concentrations of $2.8 \mathrm{~m}$ and $5.6 \mathrm{~m}$. The differences might be a consequence of contact ion pair formation in CsI solutions at these concentrations [18]. 
It can be seen from figure 1 that both $\mathrm{I}^{-}$and $\mathrm{Cs}^{+}$form very weak hydration shells. The first neighbour Cs-O distance at $3.22 \AA$ is by about $0.5 \AA$ shorter than the I-O one and accordingly it is more pronounced. While a lone pair orbital of the hydration shell water molecules is directed toward $\mathrm{Cs}^{+}$, preferentially a linear hydrogen bond is formed with $\mathrm{I}^{-}$. As there are no well defined first minima in the Cs-O and I-O RDFs the hydration numbers have got just a limited significance and are found to be 8 for $\mathrm{Cs}^{+}$and 9 for $\mathrm{I}^{-}$. The positions of the first maxima in the Cs-H and I-O RDFs almost coincide. The limited information, especially as far as the dynamical properties of the $\mathrm{Cs}^{+}$hydration shell are concerned, derived so far from simulations, can easily be overcome by much longer simulations. No problems are to be expected.

\subsection{The strontium ion}

\subsubsection{Structure}

It can be seen from figure 1 that the hydration shell of the doubly charged $\mathrm{Sr}^{2+}$ is much more pronounced than those for $\mathrm{Cs}^{+}$and $\mathrm{I}^{-}$. The first maximum in the Sr-O RDF appears at $2.83 \AA$ and its height is three times that for $\mathrm{Cs}^{+}$. Its hydration number amounts to about 10 [19]. There is a strong preference for an orientation of the hydration shell water molecules where the dipole moment points away from the ion in accordance with the position of the first peak in the Sr-H RDF at $3.35 \AA$. Obviously, the $\mathrm{Sr}^{2+}$ has a well defined second hydration shell at $5 \AA$, again different from $\mathrm{Cs}^{+}$and $\mathrm{I}^{-}$.

\subsubsection{Dynamical properties}

In the MD simulation of the $1.1 \mathrm{~m} \mathrm{SrCl}_{2}$ solution the flexible BJH water model is employed which permits the calculation of the effect of the ions on the spectral densities of the intramolecular vibrations. The potentials describing the ion-water and ion-ion interactions have been derived from ab initio calculations [19].

The self-diffusion coefficient of $\mathrm{Sr}^{2+}$ has again been calculated from the velocity autocorrelation function using the Green-Kubo relation. It is found to be $(0.6 \pm$ $0.1) \cdot 10^{-5} \mathrm{~cm}^{2} / \mathrm{s}$ similar to that of $\mathrm{Li}^{+}$but only half of that of $\mathrm{Cl}^{-}$. The self-diffusion coefficients of the ions in electrolyte solutions do not just depend upon their masses but also on the strength of their interaction with the hydration shell water molecules, a consequence of their sizes and charges.

The pronounced hydration shell (figure 1) is also responsible for the position of the maximum in the spectral density of the hindered translational motion of $\mathrm{Sr}^{2+}$, calculated by Fourier transformation of its velocity autocorrelation function. The maximum is found at $125 \mathrm{~cm}^{-1}$, more than twice as high as that of $\mathrm{Cl}^{-}$although the mass of $\mathrm{Cl}^{-}$is only half of that of $\mathrm{Sr}^{2+}$.

The spectral densities of the liberational motions of the hydration shell water molecules of $\mathrm{Sr}^{2+}$ remain unchanged relative to bulk water for the rotation around their dipole moment axis. This results from the fact that the dipole moment points 


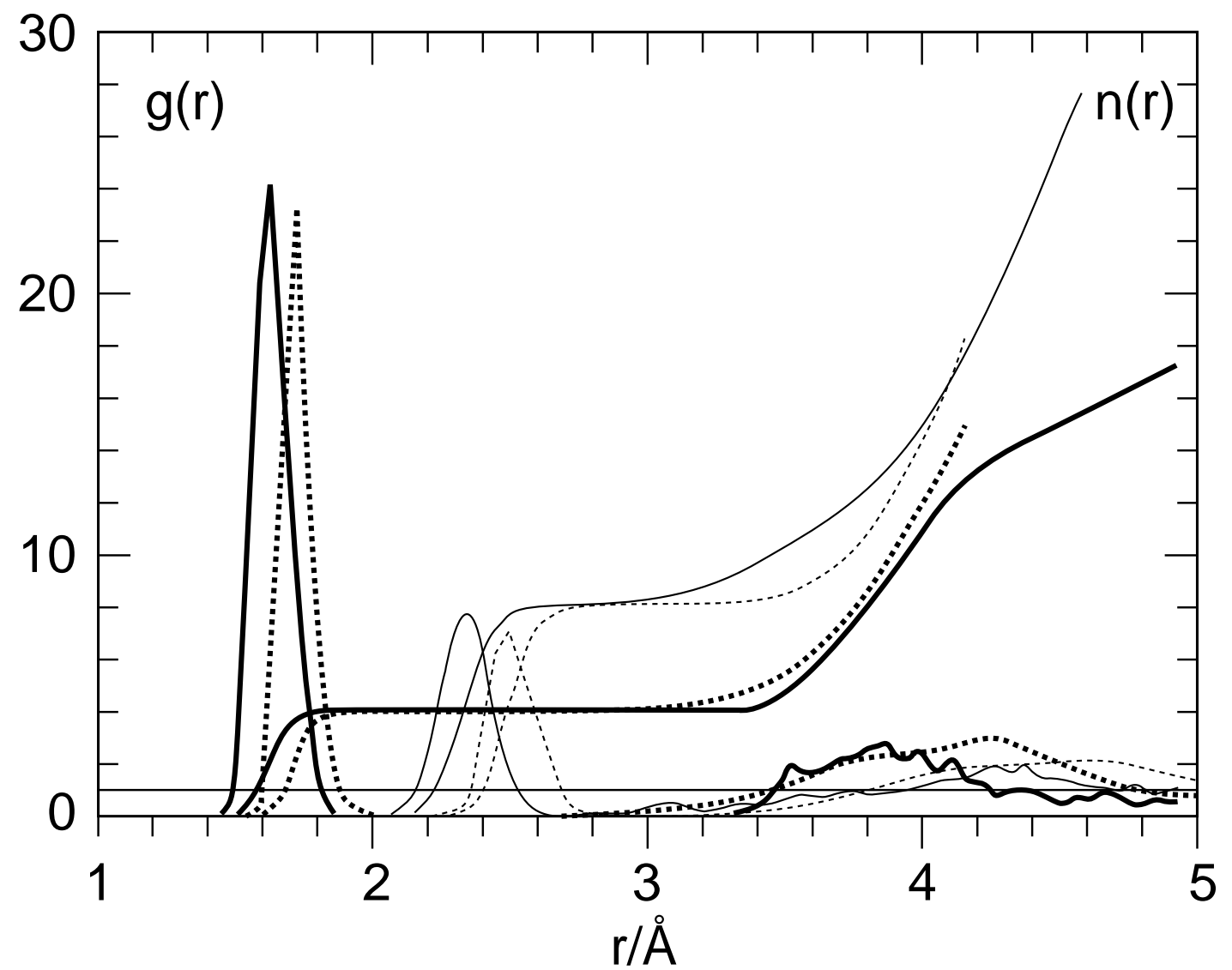

Figure 2. The beryllium-oxygen (thick lines) and beryllium-hydrogen (thin lines) radial distribution functions and the corresponding running integration numbers from an ab initio MD simulation (full) and an MD simulation with a three-body potential for the ion-water interaction (dashed).

away from the ion and the hindrance of the rotation results practically only from the interactions with the neighbouring water molecules in the hydration shell as in the case of bulk water. The maxima of the spectral density around the other two principal axes are blueshifted by about $100 \mathrm{~cm}^{-1}$ because of the interactions with $\mathrm{Sr}^{2+}$.

The influence of $\mathrm{Sr}^{2+}$ on the bending vibration of the hydration shell water molecules is very small. But the symmetric as well as the asymmetric O-H stretching frequencies show a redshift of about $140 \mathrm{~cm}^{-1}$ relative to bulk water in agreement with the corresponding increase of the bond length from 0.9753 to $0.9815 \AA$ [19].

\section{Hydration of the beryllium ion}

In agreement with experimental data, the hydration shell structures of the alkali, halide and alkaline earth ions - at least as far as the ion-oxygen distances and the hydration numbers are concerned - could be described by employing pair potentials in the simulations, except for the small, doubly charged $\mathrm{Be}^{2+}$. For this ion the 
simulation of a $1.1 \mathrm{~m} \mathrm{BeCl}_{2}$ solution - by employing pair potentials derived from $a b$ initio calculations - resulted in a beryllium-oxygen first neighbour distance of $1.75 \AA$ and a hydration number of six in disagreement with an X-ray diffraction study of a $5.3 \mathrm{~m} \mathrm{BeCl}_{2}$ solution where a Be-O distance of $1.67 \AA$ and a hydration number of four was found [2].

In order to improve the simulation, a three-body contribution to the $\mathrm{Be}^{2+}$-water interaction has been introduced which led immediately to a hydration number of four without any change in the Be-O distance [3]. Thus the question remains whether the difference in the beryllium-oxygen distance of $0.8 \AA$ has to be attributed to the remaining limitation of the potential or to the uncertainty of the experimental value.

Recently the results of a first principle MD simulation of $\mathrm{Be}^{2+}$ surrounded by 31 water molecules has been reported [4]. The Be-O and Be-H RDFs together with the running integration numbers are compared in figure 2 with those based on the simulation with the three-body potential. The new data confirm not only the hydration number of four but are also - with a Be-O distance of $1.65 \AA$ - in good agreement with the experimental result of $1.67 \AA$. In spite of the limited number of particles, it seems that the Car-Parrinello method is - at least in principle - the best way to simulate correctly the structure of the hydration shell of an ion. Unfortunately, the treatment of an extended solution with several hundred particles, with this method, seems to be out of range for the time being. Although it is known experimentally that hydrolysis will occur with the hydrated $\mathrm{Be}^{2+}$, the authors did not report any such effect in their paper.

The geometrical arrangement of the water molecules in the hydration shells of the ions is determined by the ion-water as well as by the water-water interactions. It can be calculated from knowing the positions of all particles as a function of time provided by the MD simulation. In order to achieve this aim, a coordinate system has to be introduced where the ion defines the origin, one oxygen of the hydration shell water molecules the z-axis, and a second one the xz-plane. The registration of the water positions (oxygen atoms) in this ion-centred coordinate system at several hundred time steps spread over the whole simulation run provides the ensemble and time averaged geometrical arrangement.

The densities of the projections onto the xy-plane of the oxygen atom positions of the water molecules in the first hydration shell of $\mathrm{Be}^{2+}$ and $\mathrm{Sr}^{2+}$ are shown in figure 3 in the form of axiometric drawings. Figure 3 shows unambiguously that the four water molecules in the first hydration shell of $\mathrm{Be}^{2+}$ are positioned on the vertices of a tetrahedron while the ten hydration shell water molecules of $\mathrm{Sr}^{2+}$ show no regular symmetry. They are almost uniformly distributed around the ion.

\section{Hydrolysis}

A problem of special interest remaining in Chernobyl is the hydrolysis caused mainly by the uranium and plutonium ions together with the formation of polynuclear ions. Holovko [20] has discussed this problem recently from a theoretical point of view, while Yukhnovskij et al. [21] collected relevant information on this subject 

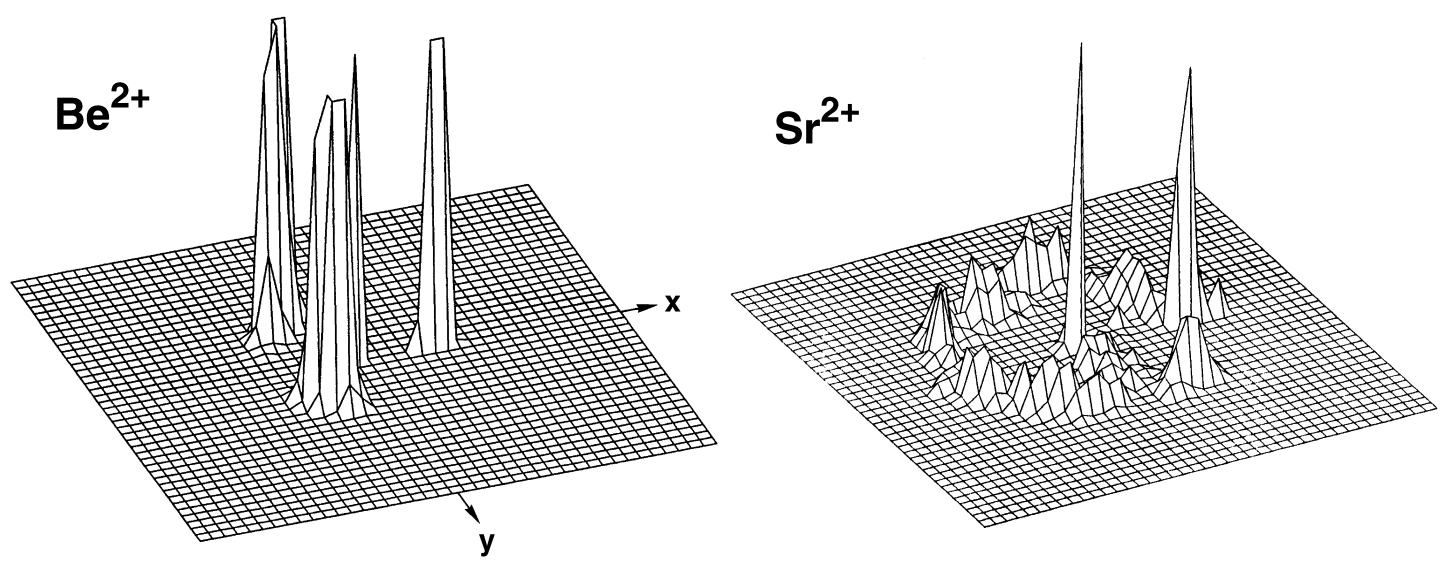

Figure 3. Densities of the projections of the oxygen atom positions of the first shell water molecules around a $\mathrm{Be}^{2+}$ and a $\mathrm{Sr}^{2+}$ onto the $x y$-plane of a coordinate system as defined in the text. The drawings are calculated from MD simulations of $1.1 \mathrm{~m} \mathrm{BeCl}_{2}$ and $\mathrm{SrCl}_{2}$ solutions.

from a chemical viewpoint. In this chapter it is pointed out in which way computer simulation and/or ab initio calculations could contribute to the understanding of these effects on a molecular level.

In order to investigate hydrolysis in a reliable way by computer simulations the first principle MD simulation has to be employed. The large computational effort necessary for this method permits only the treatment of small systems, like e.g. the simulation of the hydration of the beryllium ion discussed in the preceding chapter. Although hydrolysis caused by the $\mathrm{Be}^{2+}$ was not investigated in this paper [4], quite recently a first investigation of this type was reported by Aida et al. [6]. These authors performed a first principle simulation of the hydrolysis of methyl chloride, including explicitly 3 water molecules, and found that in this way it is possible to understand hydrolysis on a molecular level, but more water molecules have to be included explicitly in the simulation.

Simple procedures of calculating the hydrolysis constants from the free energy change have been reported for iron(III). Rustad et al. [22] performed MD simulations employing a pair potential for the iron-water interactions derived from ab initio calculations. The many-body interactions have been taken care of by employing a polarizable water model. The first hydrolysis constant was found in agreement with experimental data, but it was rather poorly reproduced. In a quite recent paper Martin et al. [23] reported density functional calculations of the free energy for the hydrated complexes $\left[\mathrm{Fe}\left(\mathrm{H}_{2} \mathrm{O}\right)_{6-\mathrm{n}}(\mathrm{OH})_{\mathrm{n}}\right]^{(3-\mathrm{n})+}$ with $\mathrm{n}=0,1,2$ and $\left[\mathrm{Fe}\left(\mathrm{H}_{2} \mathrm{O}\right)_{3}(\mathrm{OH})_{2}\right]^{+}$ 
in the gas phase. The bulk water in this solution is taken care of by a dielectric continuum. A reasonable agreement with measured free energies for the hydrolysis has been found.

Finally, density functional theory has been employed to calculate the binding energies of various hexahydrated doubly and triply charged metal ions [7]. A linear relationship between these hydration energies and the acidity constant pKa has been found. For the time being this approach, alongside of the first principle simulation method, seems not to be applicable to the uranium and plutonium ions because of the large number of electrons involved.

\section{Summary and conclusions}

It has been demonstrated above that the structural and dynamical properties of hydrated ions, which are of relevance in nuclear reactors - like cesium, iodide and strontium - can be derived reliably from Molecular Dynamics simulations. Thus for them and for many other ions in aqueous solutions the behaviour and the transport properties - important in Chernobyl - are available or can be calculated if necessary. For this kind of data the radioactivity is not of relevance.

Unfortunately, the theoretical treatment of hydrolysis, a subject which might be more important for the situation in the Chernobyl shelter than the structure and the dynamics of the hydrated ions, cannot be dealt with similarly easily. The problem originates from the fact that the more important ions in this case are uranium and plutonium and their oxides. The large number of electrons of these metal ions makes it practically impossible to derive the interaction potentials between ions and water molecules from $a b$ initio calculations with a sufficient degree of reliability. Of course, these difficulties also exclude investigating of the formation of polynuclear ions by computer simulations. It seems that for the time being the only reliable way to learn about hydrolysis effects of uranium and plutonium ions is to measure hydration shell energies and to derive from them the acidity constants via empirical relationships like the one discussed in [7].

\section{References}

1. Heinzinger K. Molecular Dynamics Simulations of Aqueous Systems. In: Computer Simulations of Fluids, Polymers and Solids (C.R.A. Catlow, S.C. Parker, M.P. Allen, eds.). Dordrecht, Kluwer Academic Publishers, 1990, p. 357-394.

2. Yamaguchi T., Ohtaki H., Pálinkás G., Heinzinger K., Probst M.M. Molecular Dynamics and X-ray diffraction study of aqueous beryllium(II) chloride solutions. // Z. Naturforsch., 1986, vol. 41a, p. 1175-1185.

3. Probst M.M., Spohr E., Heinzinger K. On the hydration of the beryllium ion. // Chem. Phys. Lett., 1989, vol. 161, p. 405-408.

4. Marx D., Sprik M., Parrinello M. Ab initio molecular dynamics of ion solvation. The case of $\mathrm{Be}^{2+}$ in water. // Chem. Phys. Lett., 1997, vol. 273, p. 360-366. 
5. Wasserman E., Rustad J.R., Xantheas S.S. Interaction potential of $\mathrm{Al}^{3+}$ in water from first principle calculations. // J. Chem. Phys., 1997, vol. 106, p. 9769-9780.

6. Aida M., Yamataka H., Dupuis M. Ab initio molecular dynamics simulations on the hydrolysis of methyl chloride with explicit consideration of three water molecules. // Chem. Phys. Lett., 1998, vol. 292, p. 474-480.

7. Chang C.M., Wang M.K. Linear relationship for acidity and stability in hexaaqua metal ions-density functional studies. // Chem. Phys. Lett., 1998, vol. 286, p. 46-50.

8. Ohtaki H., Radnai T. Structure and dynamics of hydrated ions. // Chem. Rev., 1993, vol. 83, p. 1157-1204.

9. Szász Gy.I., Heinzinger K., Riede W.O. Structural properties of an aqueous LiI solution derived from a Molecular Dynamics simulation. // Z. Naturforsch., 1981, vol. 36a, p. $1067-1075$.

10. Seitz-Beywl J., Poxleitner M., Heinzinger K. A Molecular Dynamics study of ionic hydration near a platinum surface. // Z. Naturforsch., 1991, vol. 46a, p. 876-886.

11. Szász Gy.I., Heinzinger K. Hydration shell structures in a LiI solution at elevated temperature and pressure. A Molecular Dynamics study. // Earth Planet. Sci. Lett., 1983, vol. 64, p. 163-167.

12. Spohr E., Heinzinger K. A Molecular Dynamics study of an aqueous LiI solution between Lennard-Jones walls. // J. Chem. Phys., 1986, vol. 84, p. 2304-2309.

13. Tóth G., Heinzinger K. Molecular Dynamics study of an iodide and a lithium ion at the water-liquid mercury interface. // Chem. Phys. Lett., 1995, vol. 245, p. 48-53.

14. Heinzinger K. Ionic hydration near platinum and liquid mercury surfaces. // J. Molec. Liquids, 1997, vol. 73,74, p. 239-252.

15. Szász Gy.I., Heinzinger K., Riede W.O. Self-diffusion and reorientational motion in an aqueous LiI solution. A Molecular Dynamics study. // Ber. Bunsenges. Phys. Chemie, 1981, vol. 85, p. 1056-1059.

16. Szász Gy.I., Heinzinger K. A Molecular Dynamics study of the translational and rotational motions in an aqueous LiI solution. // J. Chem. Phys., 1983, vol. 79, p. 34673473.

17. Szász Gy.I., Heinzinger K. A Molecular Dynamics study of the structure of an aqueous CsF solution. // Z. Naturforsch., 1983, vol. 38a, p. 214-224.

18. Tamura Y., Ohtaki H., Okada I. MD simulations of concentrated aqueous solutions of cesium iodide. // Z. Naturforsch., 1991, vol. 46a, p. 1083-1094.

19. Spohr E., Pálinkás G., Heinzinger K., Bopp P., Probst M.M. Molecular Dynamics study of an aqueous $\mathrm{SrCl}_{2}$ solution. // J. Phys. Chem., 1988, vol. 92, p. 6754-6761.

20. Holovko M. New aspects in the theory of aqueous electrolyte solutions: the effect of cation hydrolysis and polynuclear ion formation. // Cond. Matt. Phys., 1997, vol. 12, p. 13-25.

21. Yukhnovskii I.R., Tokarchuk M.V., Ignatyuk V.V., Kobryn A.E., Omelyan I.P., Zhelem R.I., Dmytriv G.S., Ivankiv O.L. Studies on nonequilibrium physico-chemical processes in the system "Fuel containing masses - aqueous solutions of radioactive elements". // Cond. Matt. Phys., 1997, vol. 12, p. 63-96.

22. Rustad J.R., Hay B.P., Halley J.W. Molecular dynamics simulation of iron(III) and its hydrolysis products in aqueous solution. // J. Chem. Phys., 1995, vol. 102, p. 427-431.

23. Martin R.L., Hay P.J., Pratt L.R. Hydrolysis of ferric ion in water and conformational equilibrium. // J. Phys. Chem., 1998, vol. A102, p. 3565-3573. 


\section{До гідратації іонів}

\section{К.Хайцінгер, Г.Шефер}

Інститут хімії Макса Планка, D-55020 Майнц, Німеччина

\section{Отримано 5 листопада 1998 р.}

Дана доповідь зосереджена на іонах, які утворюються в ядерних реакторах і/або становлять особливий інтерес завдяки їхньому малому радіусу і/або їхнім великим зарядам, що приводить до гідролізу. В основному будуть обговорені результати, отримані методом молекулярної динаміки, оскільки вони здатні забезпечити вичерпний і послідовний опис структурних і динамічних властивостей молекул води в гідратаційних оболонках іонів. Які б реакції між іонами і молекулами води не відбувалися, $€$ необхідним застосовувати ab initio обчислення такі, як метод Кар-Парінелло. Обговорюються труднощі, пов'язані з дослідженням цим методом іонів урану і плутонію.

Ключові слова: гідроліз, молекулярна динаміка, метод Кар-Парінелло, актиніди

PACS: 61.20.Q, 61.20.J, 71.15.Pd 